\section{Primeless B cell boosting}

\section{By Lev Osherovich, Senior Writer}

A pair of papers published in the Proceedings of the National Academy of Sciences presents two ways to jump-start antibody production using lipid vaccine adjuvants that stimulate invariant natural killer T cells. ${ }^{1,2}$ The result is rapid and efficient antibody production without having to first prime the $\mathrm{B}$ cells with helper $\mathrm{T}$ cells.

The new techniques allow for enhanced antibody production against poorly immunogenic peptides, bacterial lipids and glycoproteins. In addition, the approaches may provide new tools for vaccine development in areas such as bacterial infection.

The findings have led the authors of one of the papers to spin out a new company to develop the technology.

One study was conducted by research groups led by Facundo Batista, senior group leader at the Cancer Research UK, and Vincenzo Cerundolo, professor of immunology at the Weatherall Institute of Molecular Medicine at the University of Oxford. The other study was led by Michael Brenner, chief of the Division of Rheumatology, Immunology and Allergy at Brigham and Women's Hospital.

The PNAS studies build on previous hints that invariant natural killer $\mathrm{T}$ cells (iNKT cells) can bypass the need for helper $\mathrm{T}$ cells in stimulating antibody production by B cells. ${ }^{3}$ Both groups used a combination of cell culture and mouse experiments to bring B cells together with iNKT cells.

Whereas helper $\mathrm{T}$ cells engage $\mathrm{B}$ cells through a peptide antigen presented by major histocompatibility complex class II (MHC II) molecules, iNKT cells dock to an alternative B cell surface protein called CD1d, which presents lipid antigens.

Previous work had shown that iNKT cells can be activated by CD1d bound to a lipid called $\alpha$-galactosylceramide ( $\alpha$-GalCer), which resembles molecules found on the coating of bacterial and fungal pathogens. ${ }^{4}$

The new studies show that iNKT cells can be recruited to specific B cells by packaging $\alpha$-GalCer together with specific antigens.

"This is the first proof of concept that linking the antigen to the NKT agonist can improve B cell response," said Vincent Serra, CEO of Wittycell S.A., which is developing lipid vaccine adjuvants that stimulate iNKT cells.

\section{Draw a bead}

The strategy taken by Cerundolo and Batista's team was to manufacture silica beads coated with both an antigenic protein called hen egg lysozyme (HEL) and $\alpha$-GalCer.
In vitro, B cells recruited and activated iNKT cells when treated with $\alpha$-GalCer-HEL beads. This activation required both the lipid and the HEL antigen and could be prevented by blocking CD1d.

The activated iNKT cells secreted cytokines known to prompt $B$ cells to proliferate and make antibodies.

To prove that naturally occurring iNKT cells could be activated by $\alpha$-GalCer-HEL beads and could stimulate antibody production, the team injected wild-type mice with HEL-specific B cells together with $\alpha$-GalCer-HEL beads. This treatment led to a high, HEL-specific antibody titer.

Because $B$ cell stimulation by iNKT cells required physical proximity between $\alpha$-GalCer and HEL, injections of either HEL or $\alpha$-GalCer alone did not work.

Moreover, the $B$ cell-stimulating effect of the bead particles was specific to proteins physically near the $\alpha$-GalCer adjuvant. To show this, the researchers injected mice with $\alpha$-GalCer beads bearing ovalbumin (OVA), another model protein, and a soluble form of a third protein, chicken $\gamma$-globulin (CGG). The mice developed antibodies only against the bead-bound OVA protein but not against unbound CGG. When the bead-bound and soluble proteins were swapped, the resulting antibodies recognized only the bead-bound CGG.

"By coupling both the antigen and lipid to a particle bead, we can insure that only the antigen-specific B cell will be activated," said Cerundolo.

The team also found that B cells activated by $\alpha$-GalCer-HEL beads took a shortcut to producing IgG. Ordinarily, B cells activated by helper T cells take several months to shift their antibody production from surfacebound IgM to secreted IgG. However, B cells stimulated by iNKT cells using $\alpha$-GalCer-HEL beads produced IgG a week after immunization

Batista told SciBX this effect may be useful for eliciting rapid serum antibody production.

"The advantage of using iNKT cells and not T cells is that they don't need to be primed," he said.

\section{What's haptening?}

Brenner's team took a different approach, conjugating $\alpha$-GalCer to a 4 hydroxy-3-nitrophenyl hapten (NP hapten). Haptens are small molecules that cannot by themselves elicit $\mathrm{B}$ cell responses, and thus they resemble bacterial capsule polysaccharides such as lipopolysaccharide (LPS).

Raising antibodies against bacterial polysaccharides is a major challenge for the immune system because it cannot incorporate these molecules into peptide-presenting MHC receptors.

The team found that B cell hybridomas treated with NP- $\alpha-$ GalCer recruited and stimulated iNKT cells better than mock-treated controls did. In vivo, this iNKT cell recruitment led to NP-specific antibody production by the $\mathrm{B}$ cells.

In agreement with Cerundolo and Batista’s findings, Brenner's group found that production of antibodies against NP- $\alpha-$ GalCer required B cells to have a working CD1d lipid-binding surface molecule as well as J $\alpha 18$, the corresponding receptor on the iNKT cell.

The study's lead author, Elizabeth Leadbetter, a research fellow in the 
Division of Rheumatology, Immunology and Allergy at Brigham and Women's Hospital, told SciBX that raising antibodies against a "model antigen" like NP shows that it is possible to harness the adjuvant effects of lipids such as $\alpha$-GalCer to "make a strong antibody response."

Leadbetter believes that eliciting antibodies against nonpeptide antigens with lipid adjuvants could lead to "an extremely efficient vaccine" against bacterial surface polysaccharides.

"This is useful for bacterial targets that are not peptides," she said. Many bacteria are effective pathogens "because they have capsules made of polysaccharide. If you can raise a good response against them, it should complement peptide antigen approaches."

\section{Outside perspectives}

Luc Teyton, professor of immunology at The Scripps Research Institute and a member of Wittycell's scientific advisory board (SAB), told SciBX that the novelty of the studies lies in the particular "flavor" of the bead and conjugate methods used to deliver $\alpha$-GalCer.

"It's certainly a very viable approach for better adjuvants in vaccines," he said.

Teyton did note that ideal vaccine adjuvants would help iNKT cells stimulate other immune cells such as dendritic cells and helper T cells, and not just B cells.

According to Paul-Henri Lambert, emeritus professor of pathology at the University of Geneva who is also on Wittycell's SAB, an outstanding question is whether such fast-acting iNKT-based antibody responses could have a lasting effect after the initial vaccination.

After stimulation by helper T cells, B cells develop into memory cells that can launch a robust antibody response without $\mathrm{T}$ cell help. It is unknown whether $B$ cells activated by $\alpha$-GalCer beads or conjugates form memory cells.

Batista told SciBX, however, that B cell memory is not always needed for effective vaccination.

According to Batista, antibody titer in the serum can stay very high, suggesting that activated B cells migrate into the bone marrow and develop into long-lived plasma cells. He also noted that the high titer of antibodies produced by iNKT cell-stimulated B cells could persist in circulation for a long time.

\section{The lipid space}

Researchers from both groups agreed the clear next step is to show that $\alpha$ GalCer-based adjuvants can be used to boost antibody response against clinically relevant pathogens.

"Streptococcus pneumoniae is an obvious target," said Leadbetter. Antibodies against $S$. pneumoniae's polysaccharide coat protect against infection, but she noted current polysaccharide vaccines do not provide complete protection.

Batista told SciBX the high specificity and speed of the bead-based approach could be adapted for vaccines against fast-mutating targets like HIV and tumors, where conventional immunotherapies have failed.

Wittycell's approach is similar to the work described in the Brenner study, according to Serra. The company is developing synthetic derivatives of $\alpha$-GalCer as customized vaccine adjuvants to modulate cytotoxic T cell and B cell activity. ${ }^{5}$

Wittycell's preclinical programs have yielded proof-of-concept prophylactic vaccine adjuvants that work efficiently in influenza and other infectious disease models, Serra told SciBX. The company expects to start Phase I trials of undisclosed lead candidates in the middle of 2009.

Previous efforts to develop $\alpha$-GalCer as a monotherapy led to KRN7000, from Kirin Brewery Co. Ltd., which has undergone Phase I trials for solid tumors, $\mathrm{HBV}$ and HCV. ${ }^{6}$ ( http://clinicaltrials.gov/ct2/show/ NCT00363155; http:/clinicaltrials.gov/ct2/show/NCT00352235.)

Cytheris S.A.'s CYT209, a second-generation glycoceramide based on $\alpha$-GalCer, is in preclinical testing as an adjuvant for therapeutic vaccines.

Leadbetter told SciBX that her team's work is the subject of a pending patent and is available for licensing through Brigham and Women's Hospital.

Cerundolo and Batista have filed patents on their methods and have teamed up with Robert Burns to start Immunox Ltd. Burns was CEO of Celldex Therapeutics Inc., a cancer vaccine company that was acquired by Avant Immunotherapeutics Inc. in March.

According to Cerundolo, the parties are in discussions to license the technology described in his and Batista's study to Immunox.

Burns told SciBX that Immunox has licensed nonglycosidic ceramide analogs of $\alpha$-GalCer developed by Cerundolo's team, which activate iNKT cells and enhance the immune response.?

The major challenge in developing lipid iNKT agonists is to tone down the potency while achieving sufficient specificity, according to Burns. $\alpha$ GalCer is "far too potent" at activating iNKT cells, paradoxically leading to "a hyporesponsive state that's not very helpful" for vaccination, he said.

Burns believes Immunox's portfolio of iNKT agonists together with Cerundolo and Batista's bead-based delivery method will allow the company to target a range of indications. The company initially will focus on bacterial and malarial pathogens with poorly immunogenic antigens, he said.

Burns told SciBX that Immunox has grant support from the Ludwig Institute for Cancer Research and is in the process of obtaining series A funding.

\section{REFERENCES}

1. Barral, P. et al. Proc. Natl. Acad. Sci. USA; published online June 11, 2008; doi:10.1073/pnas.0802968105 Contact: Facundo Batista, Cancer Research UK, London, U.K. e-mail: facundo.batista@cancer.org.uk

2. Leadbetter, E.A. et al. Proc. Natl. Acad. Sci. USA; published online June 11, 2008; doi:10.1073/pnas.0801375101

Contact: Michael Brenner, Brigham and Women's Hospital, Boston, Mass. e-mail: mbrenner@rics.bwh.harvard.edu

3. Galli, G. et al. J. Exp. Med. 197, 1051-1057 (2003)

4. Kawano, T. et al. Science 278, 1626-1629 (1997)

5. Maggos, C. BioCentury 15(19), A13; April 23, 2007

6. Giaccone, G. et al. Clin. Cancer Res. 8, 3702-3709 (2002)

7. Silk, J.D. et al. J. Immunol. 180, 6452-6456 (2008)

COMPANIES AND INSTITUTIONS MENTIONED

Avant Immunotherapeutics Inc. (NASDAQ:AVAN), Needham, Mass. Brigham and Women's Hospital, Boston, Mass.

Cancer Research UK, London, U.K.

Cytheris S.A., Paris, France

Immunox Ltd., Oxford, U.K.

Kirin Brewery Co. Ltd. (Tokyo:2503; Pink: KNBWY), Tokyo, Japan

Ludwig Institute for Cancer Research, New York, N.Y.

The Scripps Research Institute, La Jolla, Calif.

University of Geneva, Geneva, Switzerland

Weatherall Institute of Molecular Medicine, University of Oxford,

Oxford, U.K.

Wittycell S.A., Paris, France 